\title{
CORRESPONDENCE.
}

\section{To the Editor of the AERonautical Journal.}

DEAR SIR,-There are two points of interest in connection with the Langley machine which appear to have been overlooked in Mr. Griffith Brewer's paper and also in the discussion which followed.

The first point is, that Langley was attempting to fly in 1903 with a machine having a loading of about i 3 ounces to the square foot. I do not know whether this is an impossible task or whether it has ever been performed, but it would be interesting to know whether, in addition to attempting to fly, Langley was not trying to make a performance which has never even yet, with all the flying experience of to-day, been accomplished, namely to fly with a loading of less than Ilb. to the sq. ft.

The other point will only be within the knowledge of visitors to the U.S. Museum at Washington. There, in the hall, two models are suspended, one model that of Hargrave, which is labelled "Hargrave Flying Machine. Driven by compressed air engine. Flew $3 \mathrm{r} 2 \mathrm{ft}$. at Clifton, N.S. Wales, in i $89 \mathrm{r} . "$ This model hangs in a modest little corner shaded by the gallery of the Museum. Out in the open, lighted by the windows above the gallery, is suspended the larger Langley model, labelled as follows :-"Langley Flying Machine. The first successful flight made by a machine heavier than air driven by its own power was made by this steam flying machine on May 6, 1896 , at Quantico, Virginia, over the Potomac River, with a steam pressure of I50 pounds."

What I should be interested to know, would be what the word "successful" means on the Langley model. If you omit the word "successful," the label is obviously incorrect, because the Langley model did not make the first flight by a machine heavier than air driven by its own power, because of Hargrave's model which did this five years earlier. There is some subtle difference, therefore, in the word "successful," which distinguishes the Langley model from the Hargrave model, and for the benefit of the general visitors to the Museum it would be well to have some explanation of the Smithsonian definition of the word "successful." Is it the same as the word "substantially," or " practically" ? As the well-known judge once said, when he was told that a door was "practically" shut, he knew very well it was open. No doubt the word " successful" refers to the duration of the flight and the size of the machine. It would apparently relate to the duration only, because when the Hammondsport machine was tried at Hammondsport later and flew less than $3^{1} 2 \mathrm{ft}$., it was "successful " according to the official report. What may therefore be successful in a large machine is apparently not successful in a small one. No doubt some of the Smithsonian scientists can help to elucidate the meaning of this elusive word.-Yours truly,

750, Prospect Avenue, Cleveland, $O$.

James Guthrie.

January 5, 1922 .

Berlin Lichterfelde,

Marthastr .5.

To the Editor of the Ärronautical Journat.

Dear Sir,-Many thanks for sending the Ä̈ronautical Journal, the contents of which has found my greatest interest.

As I have always been the fellow worker of my deceased brother in his aeronautical researches, I am well informed about the proceedings in the investiga- 